\title{
Shifting interactions among bacteria, fungi and archaea enhance removal of antibiotics and antibiotic resistance genes in the soil bioelectrochemical remediation
}

\author{
Xiaodong Zhao ${ }^{1}$, Xiaojing Li $i^{*}{ }^{1}$, Yue Li ${ }^{1}$, Yang Sun ${ }^{1}$, Xiaolin Zhang ${ }^{1}$, Liping Weng ${ }^{1}$, Tianzhi Ren ${ }^{1}$ \\ and Yongtao $\mathrm{Li}^{1,2^{*}}$
}

\begin{abstract}
Background: Antibiotics and antibiotic resistance genes (ARGs) are two pollutants in soil, especially ARGs as one of the top three threats to human health. The performance of soil microbial fuel cells (MFCs) fuelled with antibiotics was investigated.

Results: In this study, soil MFCs spiked with tetracycline exhibited optimal bioelectricity generation, which was $25 \%$ and 733\% higher than those of MFCs spiked with sulfadiazine and control, respectively. Compared with the non-electrode treatment, not only did functional micro-organisms change in open- and closed-circuit treatments, but also the microbial affinities, respectively, increased by 50\% and 340\% to adapt to higher removal of antibiotics. For the open-circuit treatment, the ineffective interspecific relation of micro-organisms was reduced to assist the removal efficiency of antibiotics by $7-27 \%$. For the closed-circuit treatment, an intensive metabolic network capable of bioelectricity generation, degradation and nitrogen transformation was established, which led to 10-35\% higher removal of antibiotics. Importantly, the abundances of ARGs and mobile genetic element (MGE) genes decreased after the introduction of electrodes; especially in the closed-circuit treatment, the highest reduction of $47 \%$ and $53 \%$ was observed, respectively.

Conclusions: Soil MFCs possess advantages for the elimination of antibiotics and ARGs with sevenfold to eightfold higher electricity generation than that of the control treatment. Compared with sulphonamides, the enhancement removal of tetracycline is higher, while both potential ARG propagation risk is reduced in soil MFCs. This study firstly synchronously reveals the relationships among bacteria, fungi and archaea and with ARGs and MGE genes in soil bioelectrochemical systems.
\end{abstract}

Keywords: Soil bioelectrochemical remediation, Bioelectricity generation, Antibiotic degradation, Antibiotic resistance genes, Biological interactions

\section{Background}

A recent research showed that total antibiotic usage reached 92,700 tons in China, of which veterinary antibiotics accounted for up to 52\% [1]. Antibiotics and its

\footnotetext{
*Correspondence: lixiaojing@caas.cn; yongtao@scau.edu.cn

${ }^{1}$ Agro-Environmental Protection Institute, Ministry of Agriculture and Rural Affairs, Key Laboratory of Original Agro-Environmental

Pollution Prevention and Control, MARA/Tianjin Key Laboratory of AgroEnvironment and Agro-Product Safety, Tianjin 300191, China

${ }^{2}$ College of Natural Resources and Environment, South China Agricultural University, Guangzhou 510642, China
}

metabolites are excreted into water, sediments and soils in the faeces or urine (excretion rates range from 40 to $90 \%)[2,3]$. In fact, approximately $84 \%$ of the total excretion of antibiotics (54,000 tons) stemmed from livestock industries in China [1]. Unfortunately, residual antibiotics are transferred into agricultural soils as soon as animal wastes are used as fertilizer [4]. For example, sulphonamides and tetracyclines are commonly detected in agricultural soils at concentrations of 6-33 and $5-25 \mathrm{mg} \mathrm{kg}^{-1}$, respectively [5]. In the presence of 
antibiotics, some microbial genes may mutate (or the gene expression change), which lead to the development of antibiotic resistance [6]. The horizontal gene transfer of antibiotic resistance genes (ARGs) via mobile genetic elements is an immeasurable threat to humans [7]. Therefore, developing a removal method for antibiotics and ARGs in soil is increasingly desirable.

Biodegradation is a low-cost, eco-friendly method for the removal of organic contamination from soils, but electron acceptor deficiency restricts the sustainability of this technology [8]. Promisingly, soil microbial fuel cells (MFCs) represent an emerging remediation technology that provides an inexhaustible electron acceptor and simultaneously employs micro-organisms as catalysts to directly convert chemical energy into electricity $[9,10]$. Soil MFC technology has shown excellent effectiveness in the degradation of polycyclic aromatic hydrocarbons [11], petroleum hydrocarbon [12, 13], phenol [14] and pesticides [15] in soils. Biocurrent generated from soil MFCs can stimulate the growth of functional microbial populations and thus improve their biodegradation efficiency $[13,16]$. However, the tremendous internal resistance of soil limits electron transfer and the further improvement of soil MFC performance [8]. As an amendment for soil MFCs, mixing conductive carbon fibre into soils reduced the internal resistance by $58 \%$ and increased the degradation rates of petroleum hydrocarbons by $100-329 \%$ [17]. Recently, MFC technology has performed well in degrading antibiotics (e.g. after 10 months of domestication, $85 \%$ of $20 \mathrm{mg} \mathrm{L}^{-1}$ of sulfamethoxazole was removed within $12 \mathrm{~h}$ ) and inhibiting ARGs in wastewater [18-22], but little has been reported concerning its effect on polluted soils.

During the process of biodegradation, functional micro-organisms (e.g. exoelectrogens and degraders) cannot operate alone and a complicated community network architecture is present in their microworld. For example, Anaerolineaceae fermentative bacteria break down small-molecule saccharides into shortchain fatty acids and $\mathrm{H}_{2}$, thus providing electron donors for electrochemically active bacteria such as Geobacteraceae and denitrifying bacteria such as Rhodocyclaceae and Comamonadaceae [23]. Additionally, homoacetogens were found to boost the conversion rate of acetate in MFCs by providing substances for exoelectrogens and methanogens, even these synergistic interactions occurred among fermentative bacteria, homoacetogens, exoelectrogens and methanogens [24, 25]. To date, few studies have detailed the community structures and interspecific relationships among bacteria, fungi and archaea in MFC systems concurrently.
In this study, tetracycline and sulfadiazine, which are commonly detected in soils, were selected as typical antibiotics to study in soil MFCs, with the following aims: first, to investigate the ability of soil MFCs to degrade tetracycline and sulfadiazine and to generate electricity by constructing microbial electrochemical systems; second, to explore whether soil MFCs can inhibit the occurrence of ARGs and reduce their propagation by using a Smartchip real-time PCR system; and last, to integrally reveal the change of structures and interactions of the bacterial, fungal and archaeal communities after the introduction of electrodes and further stimulation of biocurrent by $16 \mathrm{~S}$ rRNA sequencing.

\section{Results}

\section{Bioelectricity generation by the soil MFCs}

The start-up time for the soil MFCs was defined as the time needed for the voltage output to reach greater than $1 \mathrm{mV}$ (100 $\Omega$ of external resistance). The startup time of TC (closed-circuit treatments spiked with tetracycline) was $9 \mathrm{~h}$ (Fig. 1a and Additional file 1: Figure S1a), which was 7-8 h earlier than those of SC (closed-circuit treatments spiked with sulfadiazine, $16 \mathrm{~h}$ ) and CC (closed-circuit treatments without the addition of antibiotics, $17 \mathrm{~h}$ ). Within 1-3 days, the first peak of current density was $65 \pm 6 \mathrm{~mA} \mathrm{~m}^{-2}$ for TC, which was $23 \%$ and $196 \%$ higher than those for SC $\left(53 \pm 1 \mathrm{~mA} \mathrm{~m}^{-2}\right)$ and $\mathrm{CC}\left(22 \pm 1 \mathrm{~mA} \mathrm{~m}^{-2}\right)$, respectively. On the 27th day, the maximum current densities of TC and SC achieved $136 \pm 3$ and $109 \pm 6 \mathrm{~mA} \mathrm{~m}^{-2}$, respectively, while that of $\mathrm{CC}$ was only $47 \pm 1 \mathrm{~mA} \mathrm{~m}^{-2}$ on day 19. The accumulated charge output was $1132 \pm 48$ $\mathrm{C}$ for TC and $940 \pm 82 \mathrm{C}$ for SC, which were sevenfold to eightfold more than that of CC $(142 \pm 26 \mathrm{C})$ (Fig. 1b). Power density and polarization curves were analysed when the soil MFCs reached their maximum current densities (Fig. 1c, d), which were as follows: $\mathrm{TC}\left(31 \pm 1 \mathrm{~mW} \mathrm{~m}^{-2}\right)>\mathrm{SC}\left(25 \pm 7 \mathrm{~mW} \mathrm{~m}^{-2}\right)>\mathrm{CC}$ $\left(1.8 \pm 0.03 \mathrm{~mW} \mathrm{~m}^{-2}\right)$. Furthermore, the open-circuit voltages (OCVs) of $\mathrm{TC}, \mathrm{SC}$ and $\mathrm{CC}$ were $0.37 \pm 0.02$, $0.36 \pm 0.03$ and $0.18 \pm 0.01 \mathrm{~V}$, respectively (Additional file 1: Figure S1b). In terms of their individual polarization curves, the internal resistances of SC and TC were 336 and $262 \Omega$, respectively, $75-80 \%$ lower than that of CC $(1332 \Omega)$.

\section{Removal of tetracycline and sulfadiazine}

After 58 days of incubation, the removal efficiencies of tetracycline and sulfadiazine increased from $46 \pm 2.7$ to $72 \pm 3.1 \%$ and $86 \pm 0.2$ to $95 \pm 0.7 \%$ in closed-circuit MFCs compared with the corresponding non-electrode controls, respectively (Fig. 2a, b). As expected, 

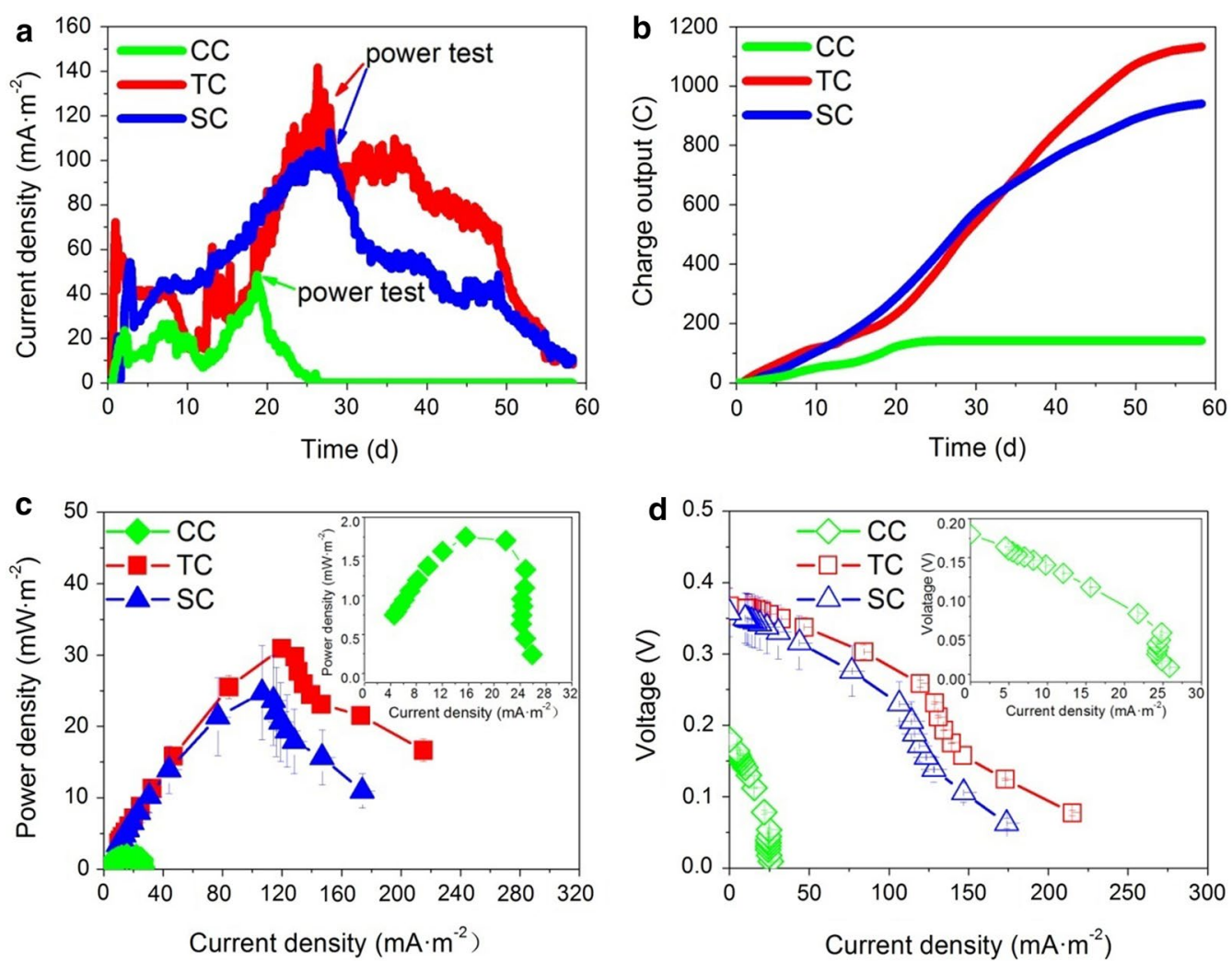

Fig. 1 Current density (a) and charge output (b) over an incubation time of 58 days, and power density (c) and polarization (d) curves of the soil MFCs. Closed-circuit treatments spiked with tetracycline, sulfadiazine and without antibiotics added are marked as TC, SC and CC, respectively. Data are the means of duplicates

the average degradation rate of TC exhibited the highest value $(70 \pm 3 \%)$, followed by those of TO (open-circuit treatments spiked with tetracycline, $66 \pm 2.5 \%)$ and TN (non-electrode treatments spiked with tetracycline, $52 \pm 6.1 \%$ ) (Fig. 2c). Meanwhile, the degradation rates of sulfadiazine showed the same trend as those of tetracycline: $\mathrm{SC}(95 \pm 0.5 \%)>\mathrm{SO}$ (open-circuit treatments spiked with sulfadiazine, $93 \pm 1.2 \%$ ) $>\mathrm{SN}$ (non-electrode treatments spiked with sulfadiazine, $87 \pm 1 \%$ ). Unexpectedly, the introduction of electrodes (open circuit) promoted the degradation of antibiotics, at rates $7-27 \%$ higher than those of corresponding non-electrode controls $(p<0.05$, Duncan's test). The concentrations in layer $C$ of the closed circuits were $15-42 \%$ lower than their corresponding layers in the open circuits (Fig. 2a, b, $p<0.05$, Duncan's test). The lowest residual concentration of TC occurred in layer A $\left(1.4 \pm 0.2 \mathrm{mg} \mathrm{kg}^{-1}\right)$ and a slight increase was found in layer $C\left(1.5 \pm 0.1 \mathrm{mg} \mathrm{kg}^{-1}\right)$, both of which were $14-16 \%$ lower than that in layer S (Fig. 2a, $p<0.05$, Duncan's test). For SC, the lowest sulfadiazine residue was observed in layer $\mathrm{C}\left(0.23 \pm 0.04 \mathrm{mg} \mathrm{kg}^{-1}\right)$, which was $9-17 \%$ lower than those in the other layers (Fig. 2b).

\section{Evolution of target genes}

In this study, thirty-seven target genes including twentyeight antibiotic resistance genes and nine mobile genetic element genes were detected (Additional file 1: Table S1). Eighteen tet genes were found in the tested soils, and the detection rates of tet $\mathrm{G}$ and tet $\mathrm{PA}$ were $100 \%(n=27)$ (Additional file 1: Figure S2). Among the sul genes, only the sul 2 gene was detected, with a $100 \%$ detection rate $(n=27)$. All MGE genes were detected and the predominant genes were intI1, Tn24 and Tn25, which had detection rates of $100 \%(n=27)$. The relative abundances of the target genes were normalized to the 16S rRNA gene (copies of gene/copies of 16S rRNA). The introduction of electrodes (open circuit) reduced the abundances of ARGs and MGE genes, which further declined under biocurrent stimulation (closed circuit), except for MGE genes in TC (Fig. 3). For example, compared with SN, these genes declined by approximately $39 \%$ in SO and showed a $14-22 \%$ decrease again in SC. Meanwhile, the abundances of ARGs and MGE genes in C and A layers were lower than those in corresponding $\mathrm{S}$ layers, especially for TC, which showed decreases of $18-54 \%$. The least abundances of ARGs occurred in layer A of TC and 

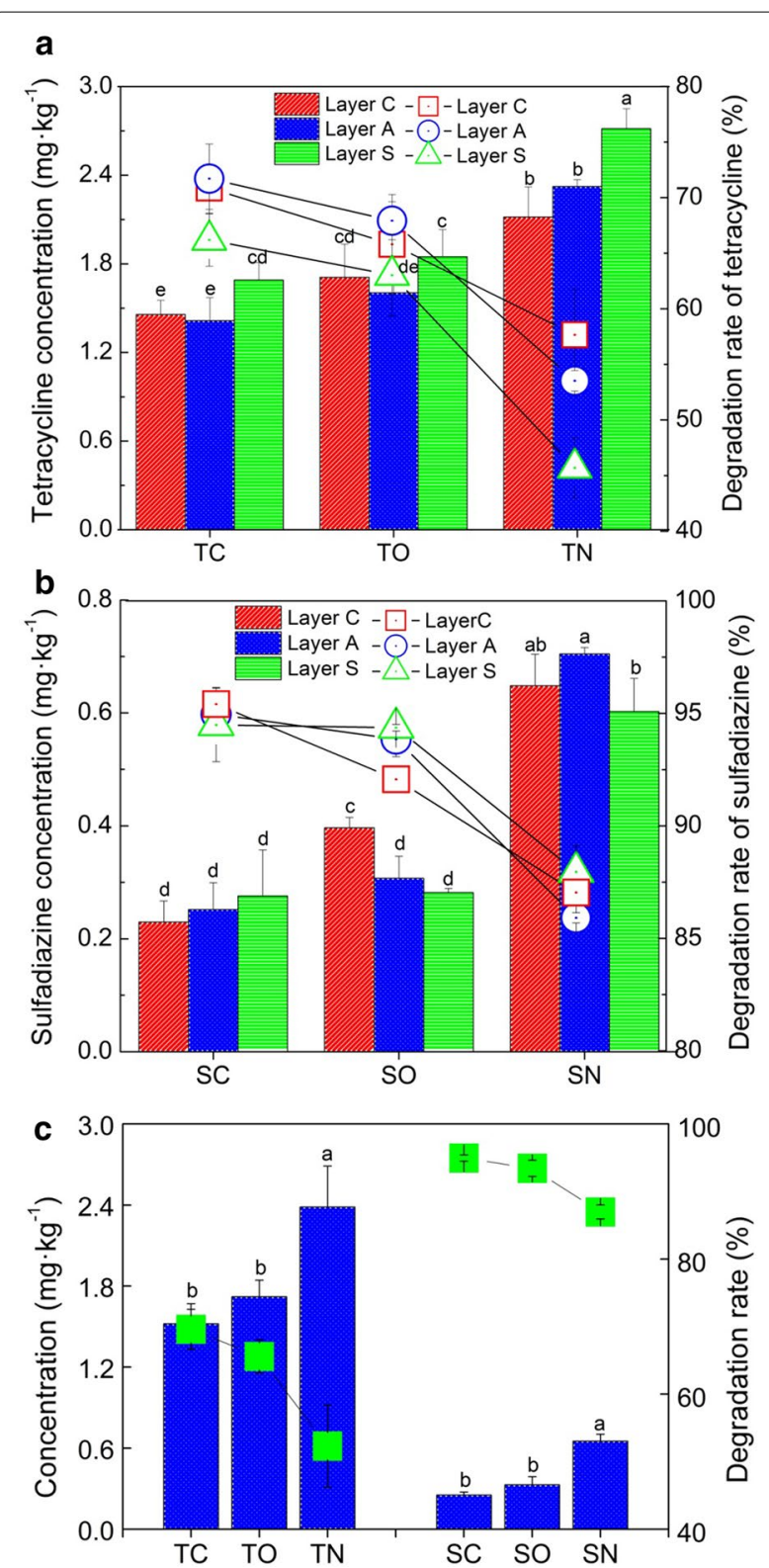

Fig. 2 Concentrations (histogram) and degradation rates (line chart) of tetracycline (a) and sulfadiazine (b) in different layers of soil MFCs. The average concentrations and degradation rates of antibiotics (c). Different lowercase letters represent significant differences at the 0.05 level among TC, TO and TN or SC, SO and SN, respectively. The closed-circuit, open-circuit and non-electrode treatments spiked with tetracycline were, respectively, labelled as TC, TO and TN; those spiked with sulfadiazine were, respectively, labelled as SC, SO and SN

layer $\mathrm{C}$ of the $\mathrm{SC}$, consistent with the residual antibiotic concentrations in TC and SC.

\section{Microbial communities}

A total of 73,327-95,166, 52,654-95,683 and 75,51594,890 effective tags with average lengths of 253, 221 and $280 \mathrm{bp}$ were acquired for the bacterial, fungal and archaeal communities, respectively, through 16S rRNA amplicon sequencing of soil samples; furthermore, 1757-5392, 400-859 and 127-1006 operational taxonomic units (OTUs) at a 97\% similarity clustered, respectively (Additional file 1: Table S2). Meanwhile, the Good's coverage estimators were all above $98 \%$, indicating that the sequencing depths were adequate for the microbial communities.

\section{Bacterial community}

The Shannon and Chao1 indices of the bacterial community were more sensitive to the addition of sulfadiazine than that of tetracycline (Additional file 1: Table S3). Compared with those of $\mathrm{CC}$, the SC indices exhibited decreases of $9-25 \%$. Meanwhile, the SC layer S indices decreased by $28-50 \%$ compared to those of SN (Additional file 1: Table S4).

Proteobacteria, Firmicutes and Bacteroides were the top three phyla, and their abundances accounted for $52-84 \%$ of the total bacterial community in all samples (Fig. 4a). Compared with the corresponding non-antibiotic treatments, the OTUs of Proteobacteria increased up to $18 \%$ with antibiotic addition, while Bacteroides decreased by $19-69 \%$ (Fig. $4 d-f$ ). Compared with SN, the abundance of Proteobacteria increased by $5 \%$ in SO and further increased by $16 \%$ in SC. The introduction of electrodes slightly decreased the abundances of Firmicutes and Bacteroides in treatments spiked with tetracycline (3-6\%), whereas obvious increases of $28-81 \%$ were observed under biocurrent stimulation. Higher abundances of Betaproteobacteria and Gammaproteobacteria were observed in layer $\mathrm{S}$ in all treatments, whereas the abundance of Deltaproteobacteria in layers A and $C$ was $47-212 \%$ and $56-388 \%$ higher than that in layer $\mathrm{S}$, respectively (Additional file 1: Figure S3b). Species of Firmicutes (mainly Clostridia and Bacillus, 89-96\%) clustered in layer A, such as in SC, where $227-364 \%$ of growth was viewed in layer A compared to the other layers (Additional file 1: Figure S3c). Bacteroides was primarily found in layer A, except for in SC and $\mathrm{SO}$ (Additional file 1: Figure S3d).

The distribution of the top 55 genera accounted for $20-54 \%$ of the total bacterial composition (Fig. 5a and Additional file 1: Figure S4a). The top one genus was Pseudomonas (3\%, Proteobacteria); compared with the corresponding non-antibiotic treatments, the abundance of Pseudomonas increased by $13-155 \%$ and $160-691 \%$ after the addition of tetracycline and sulfadiazine, respectively. The amounts of Methylobacter, Desulfocapsa and Geoalkalibacter rose, respectively, by $92-666 \%, 29-299 \%$ and $42-376 \%$ after the addition of antibiotics. Those of Tumebacillus, Geobacter, Acinetobacter and Pseudoxanthomonas, respectively, increased by $46-281 \%$, 

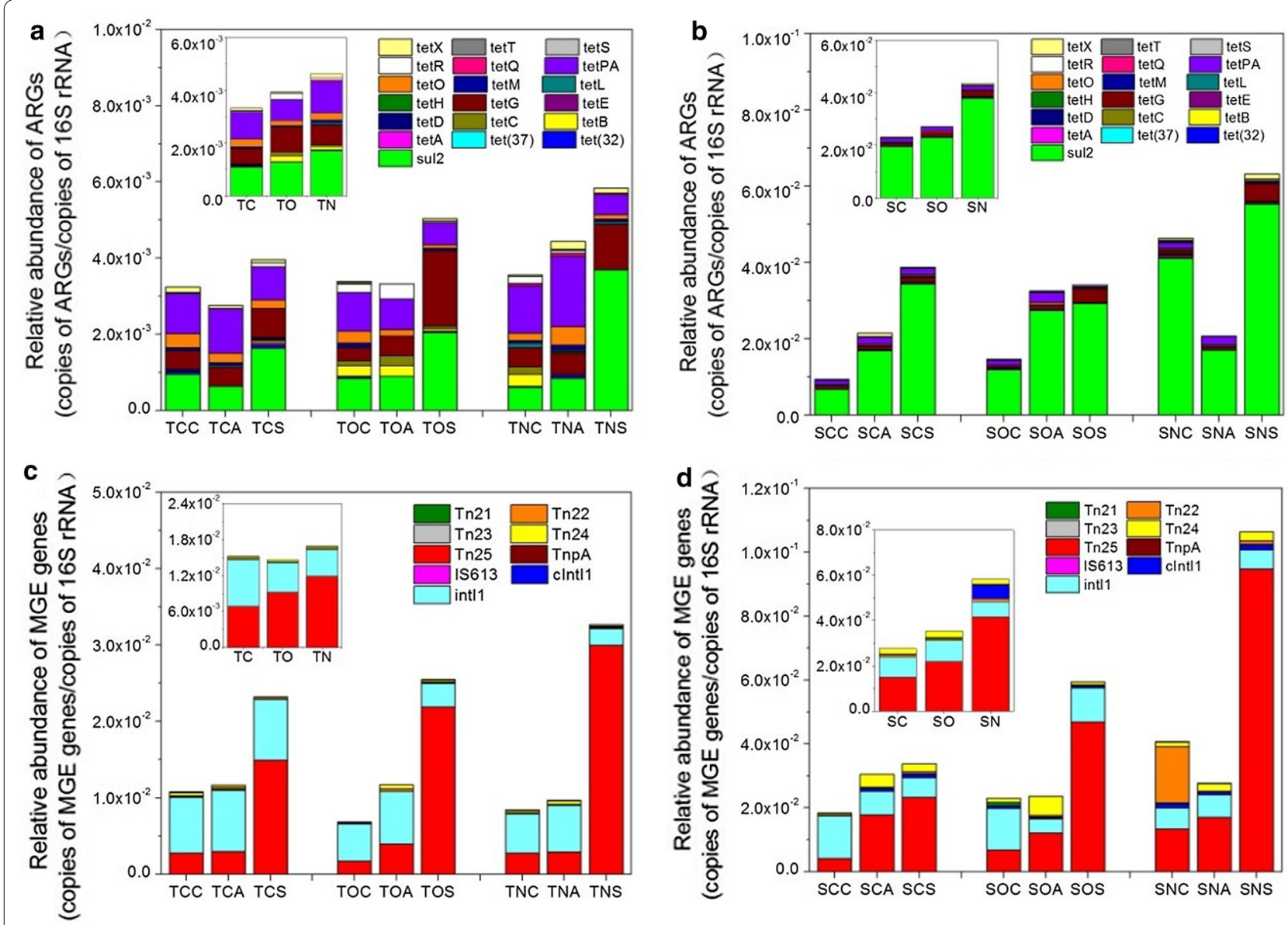

Fig. 3 Relative abundances of tet and sul genes in treatments spiked with tetracycline (a) and sulfadiazine (b). Relative abundances of MGE genes in treatments spiked with tetracycline (c) and sulfadiazine (d). TC/TO/TN/SC/SO/SNC, TC/TO/TN/SC/SO/SNA and TC/TO/TN/SC/SO/SNS represent layer $\mathrm{C}$, layer $\mathrm{A}$ and layer $\mathrm{S}$ in the same rector, respectively

91-229\%, 13-736\% and 37-175\% after the addition of tetracycline, while the abundances of Anaerolinea and Methylobacillus, respectively, increased by $13-224 \%$ and $120-557 \%$ with the addition of sulfadiazine. Compared with the corresponding non-electrode treatments, after the introduction of electrodes, the abundances of Pseudoxanthomonas and Geobacter, respectively, increased by $45 \%$ and $103 \%$ in treatments spiked with tetracycline. Relative to the corresponding open-circuit treatments, the amounts of Anaerolinea, Desulfocapsa and Tumebacillus increased by $42-60 \%, 58-69 \%$ and $24-106 \%$ after the stimulation of biocurrent, respectively. In the connected soil MFCs, the amount of Bacillus in layer A was $16-452 \%$ higher than that in other layers of the same reactor (Fig. 5a). Species of Desulfocapsa showed similar results, with 13- to 14-fold higher increases in SC. In treatments spiked with tetracycline, the amounts of Geobacter and Geoalkalibacter in layers C and A increased, respectively, by $63-285 \%$ and $132-645 \%$ compared to those in layer $\mathrm{S}$ of the closed- or open-circuit groups.

\section{Fungal community}

Compared with the corresponding non-antibiotic treatments, the Shannon (except for TN) and Chao1 (except for SC) indices increased after the addition of antibiotics, especially for TC (18-24\% of increase) (Additional file 1: Table S3). Compared with the corresponding nonelectrode treatments, the Shannon index declined by $10 \%$ and $4 \%$ with the introduction of electrodes in treatments spiked with sulfadiazine and in the non-antibiotic treatments, respectively. The index further decreased by 6-11\% under biocurrent stimulation. An opposite trend was observed for the Shannon index in treatments spiked with tetracycline.

At the phylum level, the abundance of Ascomycota accounted for $82-93 \%$ of the total composition of all libraries, followed by Zygomycota (8-15\%), 

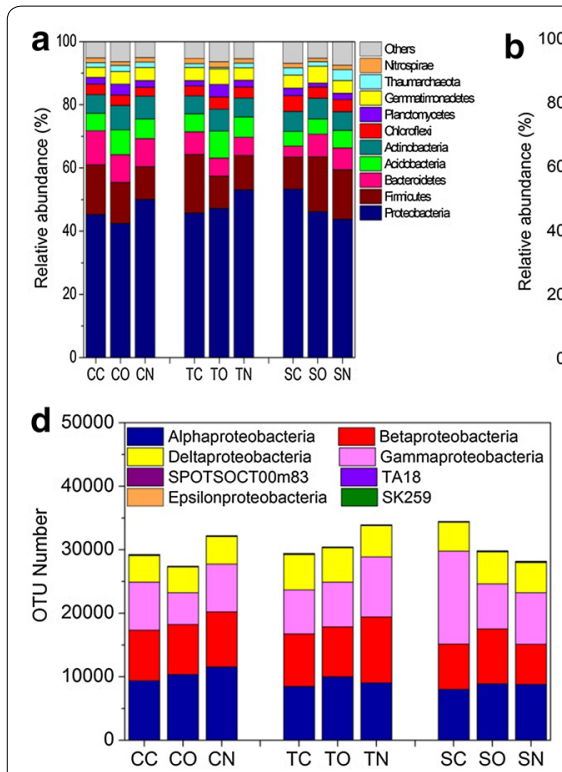

Fig. 4 Taxonomic classification of the microbial DNA sequences from soil communities in the MFC
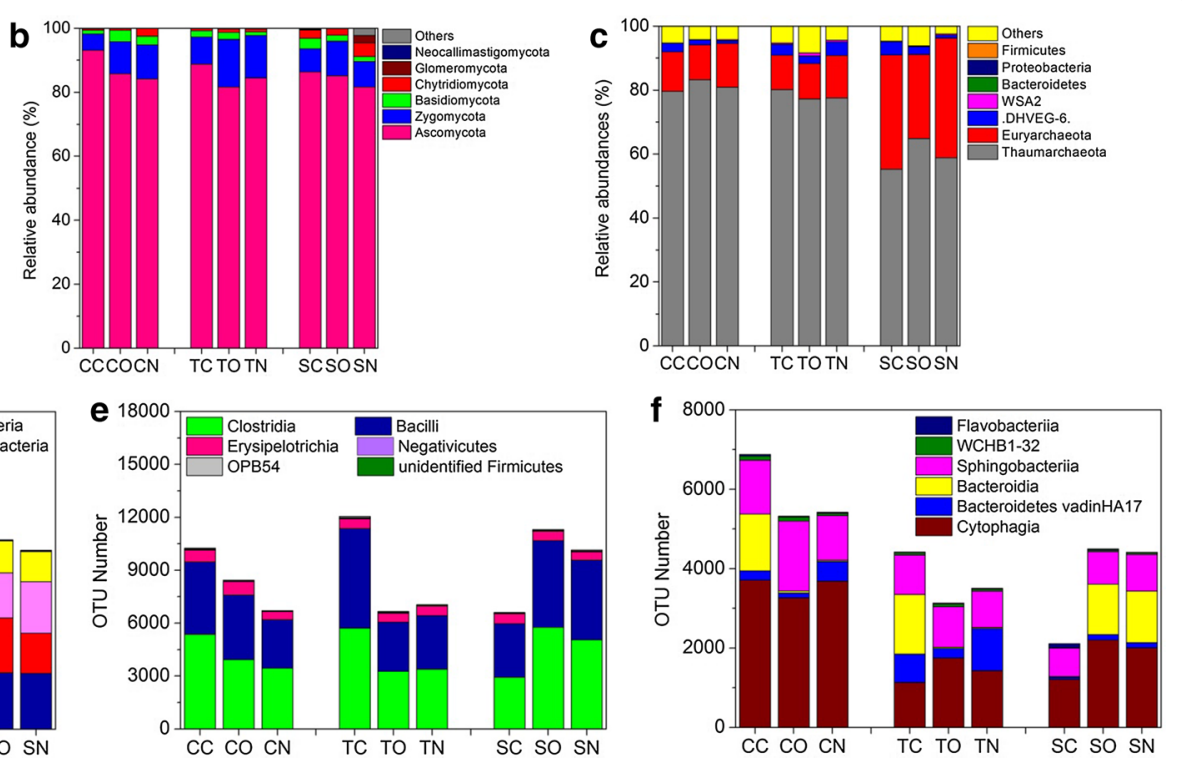
and archaea (c); those at the class level distribution of the dominant bacterial phyla of Proteobacteria (d), Firmicutes (e), Bacteroides (f). CC represents the closed-circuit treatment without antibiotics added; $\mathrm{CO}$ and $\mathrm{CN}$, respectively, represent the corresponding open-circuit and non-electrode treatments
Basidiomycota (1-4\%) and Chytridiomycota (0.5-2.6\%) (Fig. 4b). Compared with the corresponding non-antibiotic treatments, the OTUs of Ascomycota decreased after the addition of antibiotics except for TN, with the highest value being 3656 OTUs. However, those of Zygomycota and Chytridiomycota increased by 8-68\% (except for $\mathrm{SN}$ ) and 51-463\% (except for TN), respectively. Compared with the corresponding non-electrode treatments, the OTUs of Ascomycota rose by 816-1858 OTUs in CO (open-circuit treatments without the addition of antibiotics) and SO and increased again by 596-3840 OTUs under biocurrent stimulation. Species of Zygomycota were more abundant in layer A than other layers (Additional file 1: Fig. S5b). In treatments spiked with sulfadiazine, the abundance of Zygomycota in layer A decreased by $16 \%$ with the introduction of electrodes compared to the non-electrode treatment, but it increased by $29 \%$ under biocurrent stimulation.

The abundances of the top 35 genera were selected to cluster the heat map and accounted for the majority of the total composition (Fig. $5 \mathrm{~b}$ and Additional file 1: Figure S4b). The top two genera were Fusarium (11\%) and Trichoderma (5\%). Trichoderma abundance rose by $64-670 \%$ and $49-191 \%$ with tetracycline and sulfadiazine added, respectively. Compared with the corresponding non-electrode treatments, after the introduction of electrodes, the amount of Trichoderma increased by $149 \%$ in treatments spiked with sulfadiazine, and it further rose by $82 \%$ by biocurrent stimulation. The amount of Kernia rose by $19-102 \%$ with the addition of antibiotics (except for SC). In connected soil MFCs, compared with the corresponding non-antibiotic treatments, the abundances of Wardomyces and Gymnoascus, respectively, increased by $14-234 \%$ and $114-506 \%$ by antibiotics added. The abundance of Wardomyces exhibited the increments of $23-148 \%$ in both open- and closed-circuit treatments spiked with antibiotics compared with the corresponding non-electrode treatments. Furthermore, the abundance of Microascus was stimulated by the addition of antibiotics and exhibited the largest increase in the closedcircuit groups (93-122\%), followed by the open-circuit groups (32-97\%) and non-electrode groups (12-50\%). The amount of Microascus increased by $44-90 \%$ with the introduction of electrodes compared with the corresponding non-electrode treatments and further rose by $17-71 \%$ under biocurrent stimulation. Strikingly, the abundance of Microascus was predominant in layer A of the connected soil MFCs, with its highest increase being 55 times that in other layers of the same reactor (Fig. 5b).

\section{Archaeal community}

Compared with the corresponding non-antibiotic treatments, the Chao1 index rose by $48-84 \%$ in treatments spiked with tetracycline (Additional file 1: Table S3). Compared with the corresponding non-electrode treatments, the Chao1 index increased by $12-31 \%$ with the introduction of electrodes and further increased by 4-21\% under biocurrent stimulation in treatments spiked 


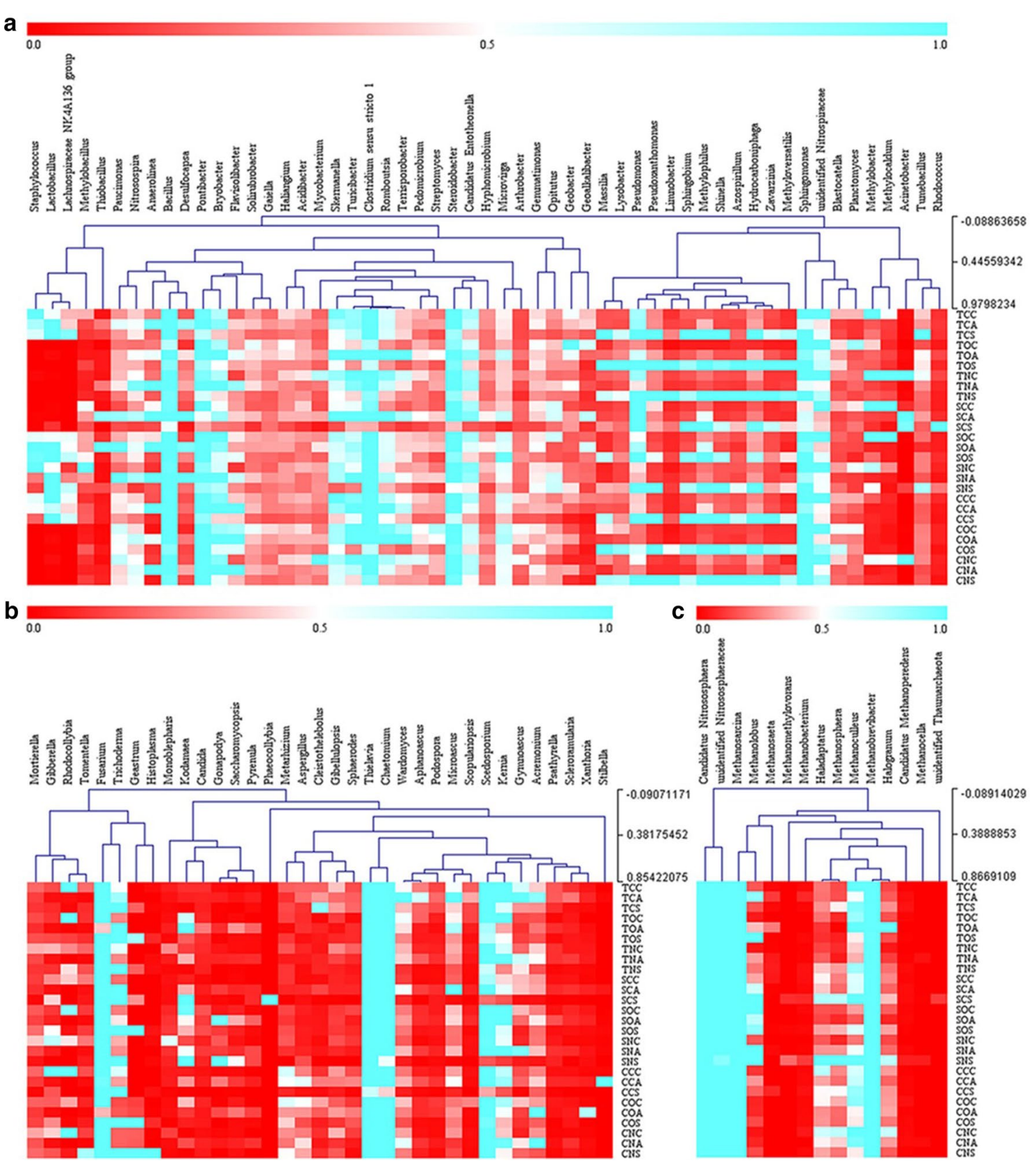

Fig. 5 Taxonomic classification of microbial DNA sequences from soil communities in different layers of MFCs at the genus level of bacteria (a), fungi (b), archaea (c)

with antibiotics. The fluctuations of the Chao1 index in layered soils were more obvious than those of the Shannon index after the addition of tetracycline, especially in layer A of TC, where the Chao1 index rose by $183 \%$ (Additional file 1: Table S4).

Thaumarchaeota and Euryarchaeota were the dominant archaea in soil MFCs and accounted for 88-96\% of the total composition in all libraries (Fig. 4c). Compared with the corresponding non-antibiotic treatments, species of Thaumarchaeota and Euryarchaeota were more sensitive to the addition of sulfadiazine. Consequently, 22-31\% decreases were observed for Thaumarchaeota, while increases of $140-189 \%$ were found for Euryarchaeota. Compared with the corresponding non-electrode treatments, the amount of Euryarchaeota in layer A declined by $18 \%$ with the introduction of electrodes in treatments spiked with tetracycline (Additional file 1: Figure S6a); it further decreased by $47 \%$ under 
biocurrent stimulation. Opposite trends were seen in the treatments spiked with sulfadiazine.

The top 15 genera accounted for 31-91\% of the total composition (Fig. 5c and Additional file 1: Figure S4c). Candidatus Nitrososphaera (16\%, Thaumarchaeota), Methanosarcina (12\%, Euryarchaeota) and unidentified Nitrososphaeraceae (11\%, Thaumarchaeota) were the dominant genera of archaea in soil MFCs. Compared with the corresponding non-antibiotic treatments, the amount of Candidatus Nitrososphaera increased after the addition of tetracycline, with a highest value of $28 \%$; however, it fell by $15-25 \%$ after the addition of sulfadiazine. Opposite trends were observed for Methanosarcina (except for TN). Methanosarcina abundance exhibited an increase of $16 \%$ in SO compared with SN, which further increased by $10 \%$ in SC. Notably, the genus Methanosarcina was predominant in layer A of SC, with an abundance $420 \%$ higher than that in TC (Fig. 5c); meanwhile, it declined by $72 \%$ in layer A of TC compared with that of TN.

\section{Discussion}

The bioelectricity generation of $\mathrm{CC}$ was better than that of our previous work (without carbon fibre in the soil). For instance, the maximum current density and charge output of CC were, respectively, 5.7- and 3.8-fold higher than those of our previous report [26] (Additional file 1: Figure S7). Mixing carbon fibre into soil in MFCs reduced internal resistance and simultaneously promoted the electron transfer rate to the anode [17], which means that electron donors such as soil organic matters were efficiently utilized. The electricity generation of TC and SC was obviously superior to that of $\mathrm{CC}$, suggesting that soil MFC systems can directly convert antibiotics into electricity in soils, especially for tetracycline (Fig. 1b).

Previous studies have shown that tetracycline is difficult to biodegrade, whereas sulphonamides have been found to be easily assimilated as a carbon or nitrogen source for microbial growth [27, 28]. However, Wang et al. [29] stressed the essentiality of the gradual domestication of micro-organisms during the process of tetracycline removal by MFCs, and $79 \%$ of tetracycline was removed within 7 days in closed MFCs after a domestication cycle of 5 weeks. Here, no inoculation and acclimation resulted in a relatively slow tetracycline degradation efficiency. Sulfadiazine is firstly biodegraded to hydroxyl sulfadiazine and dihydroxyl sulfadiazine; these products can be further degraded to $p$-aminobenzenesulfonic acid and 2-amino-4,6-dihydroxypyrimidine [22, 30]. Interestingly, a mono-oxygenation reaction is crucial for the first two steps of sulfadiazine biodegradation, which requires electron donors and molecular oxygen [30]. Coincidentally, such an environment appeared near the air-cathode, which accelerated sulfadiazine biodegradation near the cathodic soils. Unexpectedly, the degradation rates of the antibiotics in TC and SC increased only by $2-6 \%$ over those in $\mathrm{TO}$ and $\mathrm{SO}$, respectively. A similar phenomenon was found for the targeted genes. These results suggest that there is a measurable increase in efficiency in terms of antibiotic removal and ARG control as long as the open-circuit condition in the soil MFCs is maintained. There are two possible reasons for this phenomenon: on the one hand, conductive materials can promote direct interspecies electron transfer between microbial species, thus enhancing antibiotic degradation [31]; on the other hand, the introduction of electrodes likely forms a self-induced circuit where the generated electrons are consumed in situ with the help of electron acceptors such as oxygen, nitrate and sulphate $[16,17]$.

The network analysis of ARGs, MGE genes and microorganisms was performed to reveal the potential hosts and possible propagation ways of ARGs (Fig. 6). In the present research, tetPA gene had the broadest host range, and $65 \%$ of those belonged to fungi. TnpA and $\operatorname{Tn} 23$ genes had intense links with tetPA gene. However, it lacked close links among TnpA, Tn 23 genes and the potential hosts of tetPA gene. Sul2 and tet $\mathrm{G}$ shared the same hosts with the genera of Pseudomonas, Methylophilus, Methylobacillus (bacteria); Trichoderma (fungus); Methanosarcina, Methanolobus and Methanomethylovorans (archaea). Meanwhile, close links were found among sul2, tet $\mathrm{G}$, clntl1, Tn21, Tn24 and Tn25, indicating that $\operatorname{cln} t l 1, \operatorname{Tn} 21$, $\operatorname{Tn} 24$ and $T n 25$ played significant roles in the propagation of the sul 2 and tetG. Furthermore, the above four MGE genes also showed intense affinities with those potential hosts of sul2 and tetG. Clntll gene belongs to the integron gene, which can integrate exogenous genes such as ARGs as its own expression unit and transmit them on transposons or plasmids. $\operatorname{Tn} 21, \operatorname{Tn} 24$ and $\operatorname{Tn} 25$ genes belong to the transposase gene, which usually carries non-transposon genes such as ARGs for transposition, leading to the transmission of ARGs. Previous studies have suggested that tetracycline and sulphonamide resistance genes are coded on the same MGE genes to enable spread [32, 33]. Therefore, sul 2 and tet $\mathrm{G}$ genes were probably coded on clntl1, Tn21, Tn24 or Tn 25 genes of Pseudomonas, Methylophilus, Methylobacillus, Trichoderma, Methanosarcina, Methanolobus or Methanomethylovorans for propagation. The sum relative abundance of the $c \ln t l 1, \operatorname{Tn} 21, \operatorname{Tn} 24$ and $\operatorname{Tn} 25$ genes was in the order: closed-circuit group $<$ opencircuit group $<$ non-electrode group (Additional file 1: Figure S8). It suggests that not only could the soil MFC system inhibit or delay the occurrence of ARGs, but their potential propagation risk is also controlled. In the nonelectrode treatment, antibiotic selective pressure causes microbial mutations or gene expression changes, resulting 


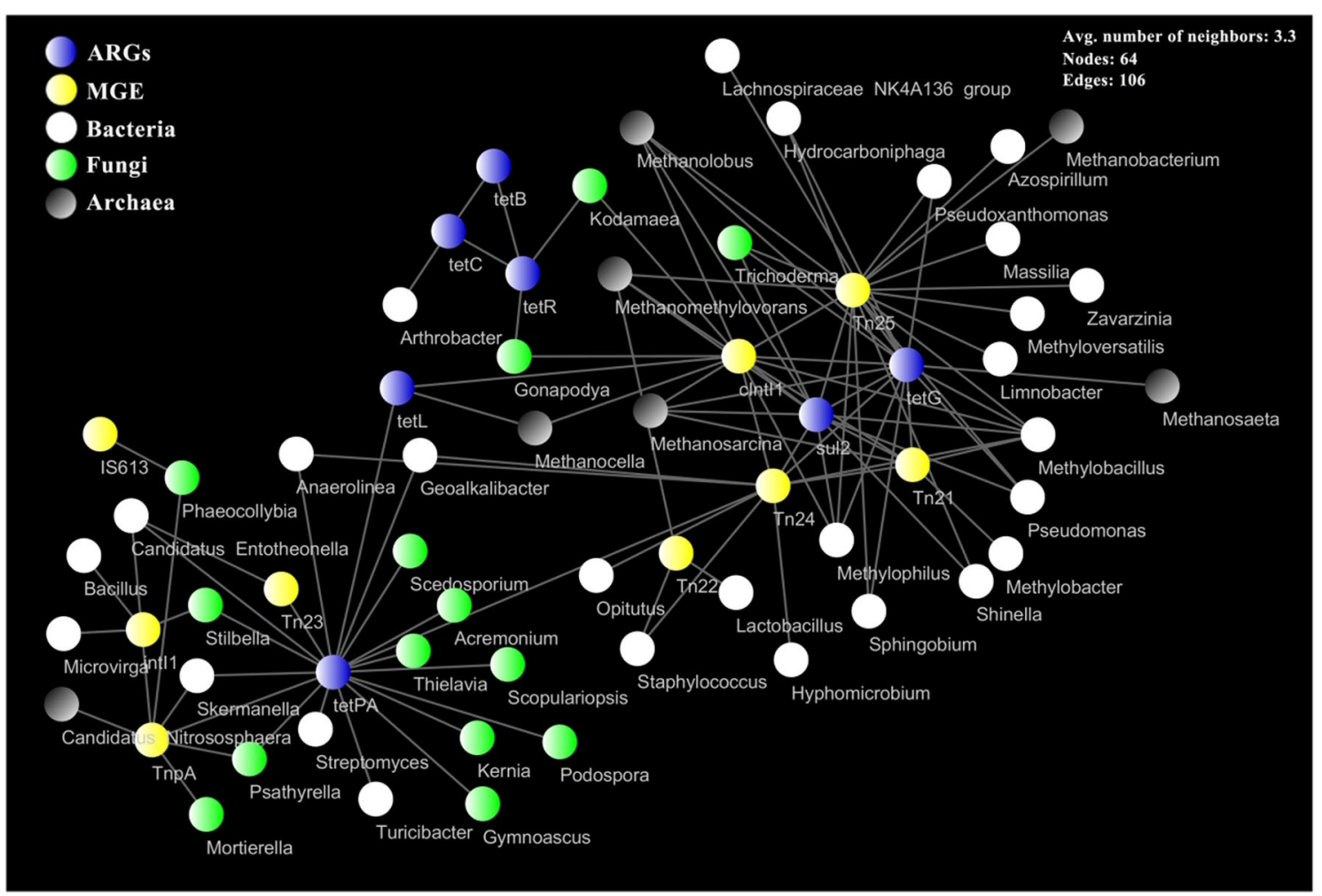

Fig. 6 Network analysis showing the connectedness among ARGs, MGE genes and micro-organisms at genus level. Each edge stands for significant the positive correlation between two items $(p<0.05$, Spearman test)

in amplification and transmission of ARGs. In the closedcircuit treatment, microbial activity is increased by biocurrent stimulation (self-induced circuits are formed in the presence of electrodes in the open-circuit group), which reduces microbial sensitivity to antibiotics, namely the selective pressure imposed by antibiotics rarely induces microbial genes mutations or expression changes in soil MFCs [34]. Besides, lower antibiotic concentration in soil MFCs may also lower its selective pressure on micro-organisms, thus reducing the probability of ARGs amplification and transmission.

Compared with non-electrode and open-circuit treatments, the microbial links increased by $14-50 \%$ in closed-circuit treatments, in which the positive links accounted for $80 \%$ of the total links (Fig. $7 \mathrm{a}-\mathrm{c}$ ). By comparison, in open-circuit and non-electrode treatments, the positive links just, respectively, accounted for $57 \%$ and $59 \%$ of the total links. To explore interspecific relationships of keystones (functional microbes), the negative links between microbes were removed, and then, microbes were further filtered by excluding the ones with the lower abundance than the corresponding nonantibiotic control (Fig. 7d-f). Although the node number of new networks in different treatments was similar, the microbial affinities (edges) in the closed-circuit group were, respectively, $193 \%$ and $340 \%$ higher than those in the open-circuit group and non-electrode group. According to the network topology parameters, the new network in the closed-circuit group exhibited the optimal performance, followed by that in the open-circuit group (Additional file 1: Table S5). For instance, compared with the non-electrode group, the shortest paths in the opencircuit group increased by $121 \%$, which further rose by $290 \%$ in the closed-circuit group. The shortest path represents the overall ability of the micro-organisms to influence their reciprocal activity or abundance for individual nodes (the higher the value is, the more stable the network is) [35]. It means that the microbial networks in the closed-circuit group and open-circuit group are more robust than that in the non-electrode group. Based on the above analysis, although the total microbial interspecific relationship in the open-circuit group was weaker than that in the non-electrode group (Fig. $7 b, c)$, the affinities of keystones were higher than those in the nonelectrode group (Fig. 7e, f). It suggests that some ineffective interspecific relationships for the biodegradation of antibiotics are discarded in the open-circuit group, which enhances the efficiency of biodegradation. 
Not only had the affinities of functional microbes been strengthened by the introduction of electrodes and the stimulation of biocurrent, but also the microbial community structure had been changed. The submodules are performed to identify some closely related microbial groups in a network and to better reveal the interspecific relationships of micro-organisms [36, 37]. Two submodules were found in the closed-circuit group by the MCODE, in which the first submodule achieved a high network score of 7 (the closest links among the microbes of a submodule) (Fig. 7d). An extremely close links was observed among Bacillus, Nitrosospira, Desulfocapsa, Geoalkalibacter, Thiobacillus, Microascus and Wardomyces. In those microbes, Bacillus sp., Desulfocapsa sp. and Geoalkalibacter sp. are recognized as electrogenic micro-organisms [38-40]. Nitrosospira sp. and Bacillus sp. involved in nitrogen cycle [41]. Moreover, a previous study indicates that Thiobacillus sp. has a potential capacity to degrade phenol [42]. In terms of the above-mentioned evidences, a complex metabolic network involving the functions of electricity generation, degradation and nitrogen transformation was established in the soil MFC system. A previous study indicated that MFCs may decrease antibiotic pressure more effectively by selecting a stand-alone functional microbial taxon more rapidly, thereby reducing the abundance of ARGs [20]. Meanwhile, there were also two submodules in the open-circuit group; except for Nitrosospira and Desulfocapsa, the genera of Pseudomonas, Pseudoxanthomonas and Trichoderma have been reported to be degraders of benzene, toluene, ethylbenzene and xylene (BTEX) [43], DDT [44] and alachlor [45], respectively (Fig. 7e). By comparison, there was only one submodule in the nonelectrode group (Fig. 7f).

\section{Conclusions}

Soil MFCs possess advantages for the elimination of antibiotics and ARGs with sevenfold to eightfold higher electricity generation than that of the control treatment. Compared with sulphonamides, the enhancement removal of tetracycline is higher, while both potential ARG propagation risk is reduced in soil MFCs. The

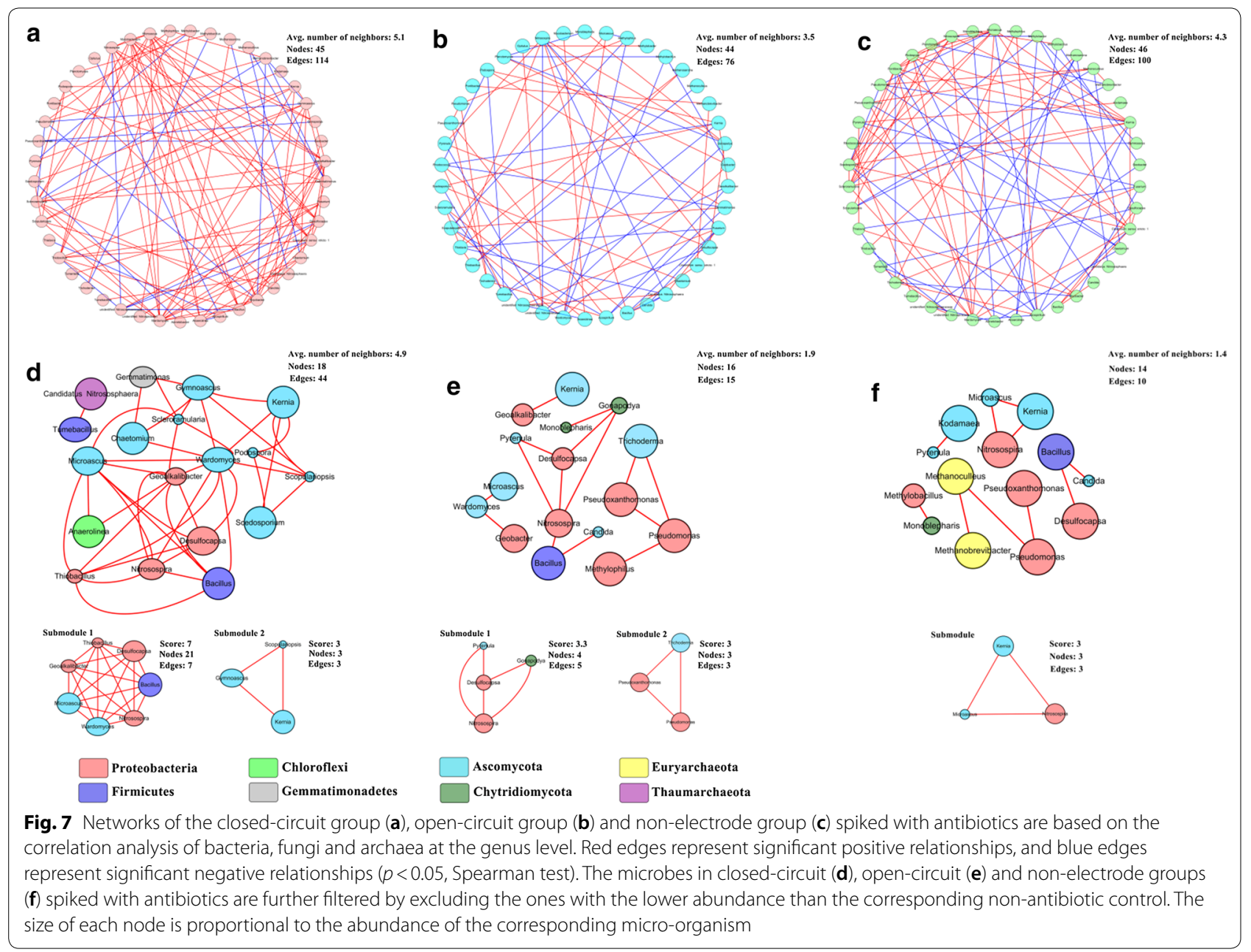


community structure and interspecific relationship of functional microbes had been reconstructed and strengthened in open- and closed-circuit treatments to adapt a disposed function of biodegradation. Some ineffective interspecific relationships for biodegradation of antibiotics were weakened after the introduction of electrodes. An intensive microbial community network capable of electricity generation, degradation and nitrogen transformation is established in closed-circuit treatments. Revealing these biological interactions is key for improving the versatile functions of bioelectrochemical remediation systems.

\section{Methods}

\section{Tested soil and chemicals}

Soils $(0-20 \mathrm{~cm}$ in depth) were collected from farmland in Xiqing, Tianjin of China. The samples were air-dried, grinded and passed through a 2-mm sieve. No antibiotics were detected in this soil. The physicochemical properties of the soil are summarized in Additional file 1: Table S6. Tetracycline and sulfadiazine were purchased from Dr. Ehrenstorfer (Germany). Chemicals such as methanol, acetonitrile and acetone were of HPLC grade.

\section{Soil MFC configuration and operation}

A single-chamber soil MFC $(6 \mathrm{~cm} \times 6 \mathrm{~cm} \times 9 \mathrm{~cm})$ was assembled with a carbon fibre cloth anode and an activated carbon air cathode (Fig. 8). The carbon fibre cloth $6 \mathrm{~cm} \times 6 \mathrm{~cm}$ in size was cleaned overnight with acetone before use, and the activated carbon air cathode $(6 \mathrm{~cm} \times 6 \mathrm{~cm})$ was manufactured using our previously described rolling-press method [46, 47]. An external resistance of $100 \Omega$ was connected to the closed-circuit soil MFCs. Carbon fibres (1 cm in length) pretreated with acetone were mixed into the tested soil as $1 \%$ of the mass fraction to reduce soil internal resistance and enhance bioelectricity generation [17]. Each closed-circuit soil MFC had a duplicate as well as corresponding open and non-electrode controls. In addition, a non-electrode control had no anode, no cathode and no carbon fibres. All soil MFCs were filled with $300 \mathrm{~g}$ of the tested soil (with $120 \mathrm{~mL}$ of deionized water).

The experiment was divided into three groups. The first group contained closed-circuit soil MFCs (labelled as TC), an open-circuit MFC (TO) and a non-electrode control MFC (TN) spiked with tetracycline $\left(5 \mathrm{mg} \mathrm{kg}^{-1}\right)$. The second group included closed-circuit soil MFCs (SC), an open-circuit MFC (SO) and a non-electrode control MFC (SN) spiked with sulfadiazine $\left(5 \mathrm{mg} \mathrm{kg}^{-1}\right)$. The last group were the controls without the addition of antibiotics (respectively, marked as $\mathrm{CC}, \mathrm{CO}$ and $\mathrm{CN}$ ). Experimental design details are provided in Additional file 1: Table S7. All treatments were incubated at a constant temperature of $30^{\circ} \mathrm{C}$.

\section{Electrochemical and chemical analysis}

The voltage $(U)$ across the $100 \Omega$ of external resistance $(R)$ was recorded using a data acquisition system (PISO813, ICP DAS Co., Ltd, Shanghai of China). Polarization and power density curves were monitored by modifying external resistances from 10,000 to $100 \Omega$. Samples were collected near the cathode (layer C), anode (layer A) and surface layer (layer S) in the soil MFCs (Fig. 8). Methods for determining the concentrations of tetracycline and sulfadiazine were modified from published protocols [48, 49]. Detailed methods are provided in Additional file 1.

\section{Target gene analysis}

Soil samples were acquired from layers C, A and S for target gene and biological analyses. Genomic DNA extraction was based on a previously published method [50]. ARGs, 16S rRNA genes, integron genes and transposase genes were detected using a Smartchip realtime PCR system (WaferGen Biosystems, USA) by Microanaly (Shanghai) Gene Technologies Co., Ltd; the primer sequences used to detect these genes are listed in Additional file 1: Table S1. The programs of PCR were based on a previous literature [51]; each PCR was performed in $100 \mathrm{~nL}$, with the following procedure: $10 \mathrm{~min}$ at $95{ }^{\circ} \mathrm{C}$, followed by 40 cycles of the following program were used for amplification: denaturation at $95{ }^{\circ} \mathrm{C}$ for $30 \mathrm{~s}$, annealing at $60{ }^{\circ} \mathrm{C}$ for $30 \mathrm{~s}$. The results were analysed using a qPCR automatic quantitative software, which advances the credibility of the data by excluding the wells with multiple melting peaks or amplification efficiency beyond the range of $90-110 \%$. Then, the target gene was considered to be detected when the threshold cycle $\left(C_{\mathrm{T}}\right)$ value was less than 31 and the deviation of three duplications was lower than $20 \%$.

\section{Biological analysis}

Total genomic DNA in the soil samples was extracted using the CTAB method. DNA concentration and purity were detected in $1 \%$ agarose gels, and DNA was diluted to $1 \mathrm{ng} \mu \mathrm{L}^{-1}$ using sterile water.

Bacterial 16S rRNA gene fragments from the V4 region were amplified by a PCR method using the universal primers 515F (GTGCCAGCMGCCGCGGTAA) and 806R (GGACTACHVGGGTWTCTAAT). Fungal 
a

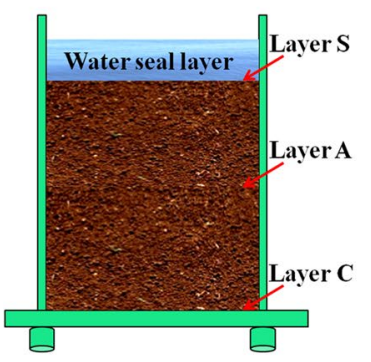

b

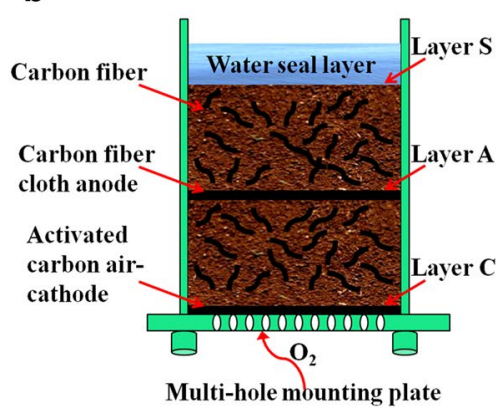

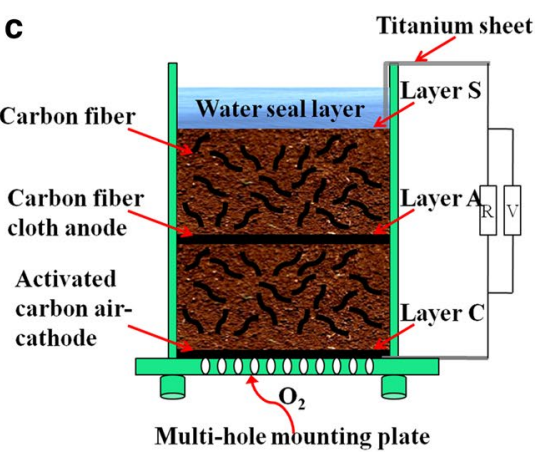

Fig. 8 The soil MFCs construction of non-electrode group (a), open-circuit group (b) and closed-circuit group (c)

16S rRNA gene fragments from the ITS1 region were amplified by PCR using the primers ITS5-1737F (GGA AGTAAAAGTCGTAACAAGG) and ITS2-2043R (GCTGCGTTCTTCATCG-ATGC). An archaeal 16S rRNA gene clone library was amplified by PCR using the primers 1106F (TTWAGTCAGGCAACGAGC) and 1378R (TGTGCAAGGAGCAG-GGAC). All PCRs were conducted with Phusion ${ }^{\circledR}$ High-Fidelity PCR Master Mix (New England Biolabs). The same quantity of $1 \times$ loading buffer (containing SYB green) was mixed with the PCR products according to their concentrations, and the samples were subjected to electrophoresis on $2 \%$ agarose gels for detection. Samples with a bright main band around 300 bp for bacteria, 200-400 bp for fungi and 350-450 bp for archaea were selected for further examination. The target strips were purified using a Gel Extraction Kit (Qiagen). Sequencing libraries were built using a TruSeq ${ }^{\circledR}$ DNA PCR-Free Sample Preparation Kit (Illumina, USA). The qualified libraries were assessed using a Qubit@2.0 Fluorometer (Thermo Scientific) as well as PCR quantitative detection and were sequenced using a HiSeq 2500 PE250 platform by the Novogene Company (Beijing, China).

\section{Network analysis}

Networks were employed to reveal the relationships among target genes (ARGs, integron genes and transposase genes) and microbial abundances at the genus level (bacteria, fungi and archaea) using the Cytoscape 3.7.0 software. In order to reduce the network complexity, the possible Spearman's rank correlations within and between target genes and microbial abundances were calculated, and a correlation between two items was considered statistically robust if $p<0.05$ (Spearman test). Nodes represent target genes or microbes, edges represent the interaction between nodes, and neighbours are nodes connected by an edge [35]. To further understand the differences between networks, a series of network topology parameters (e.g. clustering coefficient, average number of neighbours, network density and shortest paths) were calculated by network analysis tools. Besides, modular structures and groups of highly interconnected nodes were analysed using the MCODE application with the standard parameters [36].

\section{Calculations}

The current density $\left(\mathrm{mA} \mathrm{m} \mathrm{m}^{-2}\right)$ and power density $\left(\mathrm{mW} \mathrm{m}^{-2}\right)$ of each soil MFC were normalized to the project area of the air cathode $\left(A=0.0036 \mathrm{~m}^{2}\right)$ and were calculated as $I^{\prime}=U /(R \cdot A)$ and $P^{\prime}=U^{2} /(R \cdot A)$, respectively. The accumulated charge output was calculated as $Q=\int_{0}^{T} \frac{U}{R} \mathrm{dt}$, and the cycle time $(T)$ was $1800 \mathrm{~s}$. The antibiotic removal efficiency $(\beta)$ was calculated as $\beta=\left(C^{\prime}-C\right) / C^{\prime} \times 100 \%$, where $C^{\prime}$ was the concentration of the original soil and $C$ was the antibiotic residue at the end of the experiment. The relative copy number of each target gene $(\gamma)$ was calculated as $\gamma=10^{(31-C T) /(10 / 3)}$ [51]. One-way ANOVA (SPSS 18.0) was used to determine significant differences $(p<0.05$, Duncan's test) between samples, indicated by different lowercase letters. Bivariate (SPSS 18.0) was used to determine significant correlations $(p<0.05$, Spearman test) between samples.

\section{Highlights}

- Removal of antibiotics increased by $10-35 \%$ with 940-1132 C of charge output.

- Abundances of ARGs and propagation risk were decreased in soil MFCs.

- Open-circuit treatments showed a similar efficiency as closed-circuit MFCs.

- Ineffective microbial interactions reduced after the introduction of electrodes.

- Relations among key microbes were enhanced by the biocurrent stimulation. 


\section{Additional file}

\section{Additional file 1: Table S1. List of target genes. Table S2. HiSeq sequenc-} ing data of bacterial, fungal and archaea communities. Table S3. The Alpha index of bacterial, fungal and archaea communities. Table S4. The Alpha index of bacterial, fungal and archaea communities in layers. Table S5. The network topology parameters of different treatments. Table S6. The physicochemical properties of experimental soil. Table S7. The experimental design. Figure $\mathbf{S 1}$. Change of voltage within the first 24 hour (a) and open-circuit voltage (b) of soil MFCs. Closed-circuit treatments spiked with tetracycline, sulfadiazine or without antibiotics added are marked as TC, SC or CC, respectively. An external resistance of 100 $\Omega$ was connected to each closed-circuit soil MFC. Figure S2. Detection rates of ARGs (tet and sul genes) and MGE genes in tested soils ( $n=27)$. Figure S3. Taxonomic classification of bacterial DNA sequences from soi communities in different layers of MFCs at the phylum level (a), the class level distribution of the dominant phyla of Proteobacteria (b), Firmicutes (c), Bacteroides (d). CC/CO/CN/TC/TO/TN/SC/SO/SNC, CC/CO/CN/TC/TO/ TN/SC/SO/SNA and CC/CO/CN/TC/TO/TN/SC/SO/SNS represent layer $\mathrm{C}$, layer $\mathrm{A}$ and layer $\mathrm{S}$ in the same rector, respectively. Figure S4. Taxonomic classification of the microbial DNA sequences from soil communities in the MFCs at the genus level for bacteria (a), fungi (b) and archaea (c). Figure S5. Taxonomic classification of fungal DNA sequences from soil communities in different layers of MFCs the class level distribution of the dominant phyla of Ascomycota (a), Zygomycota (b), Basidiomycota (c), Chytridiomycota (d). Figure S6. Taxonomic classification of archaeal DNA sequences from soil communities in different layers of MFCs the class level distribution of the dominant phyla of Euryarchaeota (a), Thaumarchaeota (b). Figure S7. Comparison of current densities (a) and charge output (b) of soil MFCs between CC1 (in our study) and CC2. Cathodic microbial community adaptation to the removal of chlorinated herbicide in soil microbial fuel cells, Environmental Science and Pollution Research, 2018, 25(17), 16900-16912. Figure S8. The sum relative abundance of $\operatorname{Tn} 21, \operatorname{Tn} 24, \operatorname{Tn} 25$ and $c / n t / 1$ in treatments spiked with tetracycline and sulfadiazine.

\section{Abbreviations}

ARGs: antibiotic resistance genes; MFCs: microbial fuel cells; MGE: mobile genetic element; TC: closed-circuit treatments spiked with tetracycline; SC: closed-circuit treatments spiked with sulfadiazine; CC: closed-circuit treatments without the addition of antibiotics; TO: open-circuit treatments spiked with tetracycline; SO: open-circuit treatments spiked with sulfadiazine; CO: open-circuit treatments without the addition of antibiotics; TN: non-electrode treatments spiked with tetracycline; SN: non-electrode treatments spiked with sulfadiazine; CN: non-electrode treatments without the addition of antibiotics; OCV: open-circuit voltages; OTUs: operational taxonomic units

\section{Acknowledgements}

Not applicable.

\section{Authors' contributions}

$X L, X Z, Y L$ and $T R$ designed the research plan; $X L$ and $X Z$ initiated this work $X Z, X L, Y L, Y S$ and $X Z$ performed the experiments; $X L, X Z, Y L, Y S, L W$ and $X Z$ performed the data analysis; and $X L, X Z, L W, Y L$ and TR wrote the manuscript with input and discussions from all authors. All authors read and approved the final manuscript.

\section{Funding}

This study was financially supported by the National Key R\&D Program of China (No. 2017YFD0800704), the National Natural Science Foundation of China (No. 41601536) and the Central Public Interest Scientific Institution Basal Research Fund (AEPI).

\section{Availability of data and materials}

All data generated or analysed during this study are included in this published article and its additional information files.

\section{Ethics approval and consent to participate}

Not applicable.

\section{Consent for publication}

Not applicable.

\section{Competing interests}

The authors declare that they have no competing interests.

Received: 8 April 2019 Accepted: 15 June 2019

Published online: 24 June 2019

\section{References}

1. Zhang QQ, Ying GG, Pan CG, Liu YS, Zhao JL. Comprehensive evaluation of antibiotics emission and fate in the river basins of China: source analysis, multimedia modeling, and linkage to bacterial resistance. Environ Sci Technol. 2015;49:6772-82.

2. Wu XF, Wei YS, Zheng JX, Zhao X, Zhong WK. The behavior of tetracyclines and their degradation products during swine manure composting. Bioresour Technol. 2011:102:5924-31.

3. Wang C, Qu GZ, Wang TC, Deng F, Liang DL. Removal of tetracycline antibiotics from wastewater by pulsed corona discharge plasma coupled with natural soil particles. Chem Eng J. 2018;346:159-70.

4. Wang FH, Qiao M, Chen Z, Su JQ, Zhu YG. Antibiotic resistance genes in manure-amended soil and vegetables at harvest. J Hazard Mater. 2015;299:215-21.

5. Ji XL, Shen $\mathrm{QH}$, Liu F, Ma J, Xu G, Wang YL, Wu MH. Antibiotic resistance gene abundances associated with antibiotics and heavy metals in animal manures and agricultural soils adjacent to feedlots in Shanghai, China. $J$ Hazard Mater. 2012;235-236:178-85.

6. Zhu YG, Johnson TA, Su JQ, Qiao M, Guo GX, Stedtfeld RD, Hashsham SA Tiedje JM. Diverse and abundant antibiotic resistance genes in Chinese swine farms. Proc Natl Acad Sci US A. 2013;110:3435-40.

7. Qiao M, Ying GG, Singer AC, Zhu YG. Review of antibiotic resistance in China and its environment. Environ Int. 2018;110:160-72.

8. Li XJ, Wang X, Weng LP, Zhou QX, Li YT. Microbial fuel cells for organiccontaminated soil remedial applications: a review. Energy Technol. 2017:5:1156-64.

9. Lovley DR. Bug juice: harvesting electricity with microorganisms. Nat Rev Microbiol. 2006:4:497-508.

10. Li XJ, Wang X, Wan LL, Zhang YY, Li N, Li DS, Zhou QX. Enhanced biodegradation of aged petroleum hydrocarbons in soils by glucose addition in microbial fuel cells. J Chem Technol Biotechnol. 2016;91:267-75.

11. Yu B, Tian J, Feng L. Remediation of PAH polluted soils using a soil microbial fuel cell: influence of electrode interval and role of microbial community. J Hazard Mater. 2017;336:110-8.

12. Wang X, Cai Z, Zhou QX, Zhang ZN, Chen CH. Bioelectrochemical stimulation of petroleum hydrocarbon degradation in saline soil using $U$-tube microbial fuel cells. Biotechnol Bioeng. 2012;109:426-33.

13. Li XJ, Wang X, Zhang YY, Zhao Q, Yu BB, Li YT, Zhou QX. Salinity and conductivity amendment of soil enhanced the bioelectrochemical degradation of petroleum hydrocarbons. Sci Rep. 2016;6:32861.

14. Huang DY, Zhou SG, Chen Q, Zhao B, Yuan Y, Zhuang L. Enhanced anaerobic degradation of organic pollutants in a soil microbial fuel cell. Chem Eng J. 2011;172:647-53.

15. Cao X, Song HL, Yu CY, Li XN. Simultaneous degradation of toxic refractory organic pesticide and bioelectricity generation using a soil microbial fuel cell. Bioresour Technol. 2015:189:87-93.

16. Li XJ, Wang X, Ren ZJ, Zhang YY, Li N, Zhou QX. Sand amendment enhances bioelectrochemical remediation of petroleum hydrocarbon contaminated soil. Chemosphere. 2015;141:62-70.

17. Li XJ, Wang X, Zhao Q, Wan LL, Li YT, Zhou QX. Carbon fiber enhanced bioelectricity generation in soil microbial fuel cells. Biosens Bioelectron. 2016;85:135-41.

18. Wang L, Liu YL, Ma J, Zhao F. Rapid degradation of sulphamethoxazole and the further transformation of 3-amino-5-methylisoxazole in a microbial fuel cell. Water Res. 2016;88:322-8.

19. Song HL, Li H, Zhang S, Yang YL, Zhang LM, Xu H, Yang XL. Fate of sulfadiazine and its corresponding resistance genes in up-flow microbial fuel cell coupled constructed wetlands: effects of circuit operation mode and hydraulic retention time. Chem Eng J. 2018;350:920-9. 
20. Yan WF, Guo YY, Xiao Y, Wang SH, Ding R, Jiang JQ, Gang HY, Wang H, Yang J, Zhao F. The changes of bacterial communities and antibiotic resistance genes in microbial fuel cells during long-term oxytetracycline processing. Water Res. 2018;142:105-14

21. Catal T, Yavaser S, Enisoglu-Atalay V, Bermek H, Ozilhan S. Monitoring of neomycin sulfate antibiotic in microbial fuel cells. Bioresour Technol. 2018;268:116-20.

22. Wang L, You LX, Zhang JM, Yang T, Zhang W, Zhang ZX, Liu PX, Wu S, Zhao F, Ma J. Biodegradation of sulfadiazine in microbial fuel cells: reaction mechanism, biotoxicity removal and the correlation with reactor microbes. J Hazard Mater. 2018;360:402-11.

23. Lu L, Xing DF, Ren ZY. Microbial community structure accompanied with electricity production in a constructed wetland plant microbial fuel cell. Bioresour Technol. 2015;195:115-21.

24. Hari AR, Katuri KP, Logan BE, Saikaly PE. Set anode potentials affect the electron fluxes and microbial community structure in propionate-fed microbial electrolysis cells. Sci Rep. 2016;6:38690.

25. Lu L, Ren ZY. Microbial electrolysis cells for waste biorefinery: a state of the art review. Bioresour Technol. 2016;215:254-64.

26. LiY, Li XJ, Sun Y, Zhao XD, Li YT. Cathodic microbial community adaptation to the removal of chlorinated herbicide in soil microbial fuel cells. Environ Sci Pollut Res. 2018;25:16900-12.

27. Wang Y, Zhang H, Zhang JH, Lu C, Huang QQ, Wu J, Liu F. Degradation of tetracycline in aqueous media by ozonation in an internal loop-lift reactor. J Hazard Mater. 2011;192:35-43.

28. Zhang $\mathrm{S}$, Song $\mathrm{HL}$, Yang $\mathrm{XL}$, Yang $\mathrm{KY}$, Wang $\mathrm{XY}$. Effect of electrical stimulation on the fate of sulfamethoxazole and tetracycline with their corresponding resistance genes in three-dimensional biofilm-electrode reactors. Chemosphere. 2016;164:113-9.

29. Wang J, He MF, Zhang DL, Ren ZY, Song TS, Xie JJ. Simultaneous degradation of tetracycline by a microbial fuel cell and its toxicity evaluation by zebrafish. RSC Adv. 2017;7:44226-33.

30. Pan SH, Yan N, Liu XY, Wang WB, Zhang YM, Liu R, Rittmann BE. How UV photolysis accelerates the biodegradation and mineralization of sulfadiazine (SD). Biodegradation. 2014;25:911-21.

31. Park JH, Kang HJ, Park KH, Park HD. Direct interspecies electron transfer via conductive materials: a perspective for anaerobic digestion applications. Bioresour Technol. 2018;254:300-11.

32. Nonaka L, Maruyama F, Miyamoto M, Miyakoshi M, Kurokawa K, Masuda M. Novel conjugative transferable multiple drug resistance plasmid PAQU1 from Photobacterium damselae subsp. damselae isolated from marine aquaculture environment. Microbes Environ. 2012:27:263-72.

33. Jang HM, Kim YB, Choi S, Lee Y, Shin SG, Unno T, Kim YM. Prevalence of antibiotic resistance genes from effluent of coastal aquaculture, South Korea. Environ Pollut. 2018;233:1049-57.

34. Yan WF, Xiao Y, Yan WD, Ding R, Wang SH, Zhao F. The effect of bioelectrochemical systems on antibiotics removal and antibiotic resistance genes: a review. Chem Eng J. 2019;358:1421-37.

35. Rodríguez-Valdecantos G, Manzano M, Sánchez R, Urbina F, Hengst MB, Lardies MA, Ruz GA, González B. Early successional patterns of bacterial communities in soil microcosms reveal changes in bacterial community composition and network architecture, depending on the successional condition. Appl Soil Ecol. 2017:120:44-54.

36. Zheng W, Zhao ZY, Gong QL, Zhai BN, Li ZY. Responses of fungal-bacterial community and network to organic inputs vary among different spatial habitats in soil. Soil Biol Biochem. 2018;125:54-63.

37. Halary S, Leigh JW, Cheaib B, Lopez P, Bapteste E. Network analyses structure genetic diversity in independent genetic worlds. Proc Natl Acad Sci USA. 2010;107:127-32.
38. Pierra M, Carmona-Martínez AA, Trably E, Godon JJ, Bernet N. Specific and efficient electrochemical selection of Geoalkalibacter subterraneus and Desulfuromonas acetoxidans in high current-producing biofilms. Bioelectrochemistry. 2015;106:221-5.

39. You LX, Liu LD, Xiao Y, Dai YF, Chen BL, Jiang YX, Zhao F. Flavins mediate extracellular electron transfer in Gram-positive Bacillus megaterium strain LLD-1. Bioelectrochemistry. 2018;119:196-202.

40. Stams AJM, de Bok FAM, Plugge CM, van Eekert MHA, Dolfing J, Schraa G. Exocellular electron transfer in anaerobic microbial communities. Environ Microbiol. 2006;8:371-82.

41. Fang WS, Yan DD, Wang QX, Huang B, Ren ZJ, Wang XL, Wang XN, Li Y, Ouyang CB, Migheli $Q$, Cao AC. Changes in the abundance and community composition of different nitrogen cycling groups in response to fumigation with 1,3-dichloropropene. Sci Total Environ. 2019;650:44-55.

42. Oshiki M, Masuda Y, Yamaguchi T, Araki N. Synergistic inhibition of anaerobic ammonium oxidation (anammox) activity by phenol and thiocyanate Chemosphere. 2018;213:498-506.

43. Hassan HA, Aly AA. Isolation and characterization of three novel catechol 2,3-dioxygenase from three novel haloalkaliphilic BTEX-degrading Pseudomonas strains. Int J Biol Macromol. 2018;106:1107-14.

44. Wang GL, Bi M, Liang B, Jiang JD, Li SP. Pseudoxanthomonas jiangsuensis sp nov., a DDT-degrading bacterium isolated from a long-term DDTpolluted soil. Curr Microbiol. 2011;62:1760-6.

45. Nykiel-Szymańska J, Bernat P, Słaba M. Potential of Trichoderma koningii to eliminate alachlor in the presence of copper ions. Ecotoxicol Environ Saf. 2018;162:1-9.

46. Li XJ, Wang X, Zhang YY, Ding N, Zhou QX. Opening size optimization of metal matrix in rolling-pressed activated carbon air-cathode for microbial fuel cells. Appl Energy. 2014;123:13-8.

47. Li XJ, Wang X, Zhang YY, Cheng LJ, Liu J, Li F, Gao BL, Zhou QX. Extended petroleum hydrocarbon bioremediation in saline soil using Pt-free multianodes microbial fuel cells. RSC Adv. 2014;4:59803-8.

48. Martínez-Carballo E, González-Barreiro C, Scharf S, Gans O. Environmental monitoring study of selected veterinary antibiotics in animal manure and soils in Austria. Environ Pollut. 2007;148:570-9.

49. Hu W, Ma LL, Guo CS, Sha J, Zhu XW, Wang YQ. Simultaneous extraction and determination of fluoroquinolones, tetracyclines and sulfonamides antibiotics in soils using optimised solid phase extraction chromatography-tandem mass spectrometry. Int J Environ Anal Chem. 2012;92:698-713.

50. Yu BB, Wang X, Yu S, Li Q, Zhou QX. Effects of roxithromycin on ammoniaoxidizing bacteria and nitrite-oxidizing bacteria in the rhizosphere of wheat. Appl Microbiol Biotechnol. 2014;98:263-72.

51. Chen QL, An XL, Li H, Su JQ, Ma YB, Zhu YG. Long-term field application of sewage sludge increases the abundance of antibiotic resistance genes in soil. Environ Int. 2016;92-93:1-10.

\section{Publisher's Note}

Springer Nature remains neutral with regard to jurisdictional claims in published maps and institutional affiliations.

\footnotetext{
Ready to submit your research? Choose BMC and benefit from:

- fast, convenient online submission

- thorough peer review by experienced researchers in your field

- rapid publication on acceptance

- support for research data, including large and complex data types

- gold Open Access which fosters wider collaboration and increased citations

- maximum visibility for your research: over $100 \mathrm{M}$ website views per year
}

At $\mathrm{BMC}$, research is always in progress.

Learn more biomedcentral.com/submissions 